\title{
Public Attitudes towards Special Needs Students as a Result of the DSM
}

\author{
Amanda Elizabeth Lentino ${ }^{\mathrm{a}}$
}

\begin{abstract}
Although the Diagnostic Statistical Manual for Mental Disorders (DSM) is universally used in the field of psychology to diagnose individuals, it is more of a political document than a scientific one. In the original version of the DSM (1952), students with mental disorders were diagnosed solely on IQ scores. But who has the power to determine what IQ score is "normal?" The American Psychiatric Association (APA) decides who is sane and who is not, and they persuade the public to accept their claims as being objective (Caplan, 1995). Thus, as the eminent philosopher Michel Foucault (1975) argues, mental professionals create the discourse on mental disorders, and they define the roles of madness and normalcy, deficiency and intelligence. In the first DSM, one was diagnosed as severely mentally deficient if he/she had an IQ score below 50. Part of the reason as to why the term special needs has a negative connotation is due to this abysmal score. Society and medical professionals only diagnosed severe cases of mental disorders. As the years progressed, the DSM gradually changed the criteria for being "mentally deficient" or having a "mental disorder." In order to be diagnosed with profound mental deficiency, one must have an IQ score below 20 . This new criterion adds to the negative connotation for special needs students. Although these students do not fit the criterion and may have incredible IQ scores, society erroneously holds the notion that people requiring special academic needs are severely deficient. This research paper shows how the DSM has shaped public attitudes toward mental disorders while it also criticizes the concept of IQ scores.
\end{abstract}

Keywords: Asperger Syndrome, Special Needs, DSM

Many individuals with high functioning autism, commonly known as Asperger Syndrome, have been called the "geek" or even "little professors" (Silberman, 2001; Abraham, 2002; Farrell, 2004). They are dubbed these names due to their incredible cognitive abilities and intelligence quotient scores (Leech, 2004; Cowen, 2009). While these students succeed academically, especially in the areas of math and science, they suffer socially, and people refer to them as being socially awkward or socially inept. These individuals usually have poor receptive language, meaning that they have difficulty interpreting others' emotions, but they have excellent expressive language, as they express their own feelings very well. They often lack empathy, and tend to have gauche gestures or remarks (Farrell, 2004). While these individuals are ostracized by their peers, and are usually placed into special needs programs in the school districts, people should realize that these individuals are, in fact, talented (Grandin, 2005; Jurecic, 2007). Thus, some schools need to alter their Individualized Education Plans (IEP) by focusing more on the social aspect of learning. Perhaps if these "special needs" students receive the proper social skills, they might have a better chance to prosper, as they can learn to succeed both academically and socially.

In many school districts across the nation, students suffering from Asperger Syndrome are denied access into gifted programs; their rejection is usually a result of the their label (Grandin, 2005; Jurecic, 2007). "Special needs" denotes a negative connotation, causing public schools to reject these students' talents. But the term "special needs" is very broad. According to the 2004 revision of Individuals with Disabilities Education Act (IDEA), special needs or "a child with a disability" is defined as "a child with mental retardation, hearing impairments (including deafness), speech or language impairments, visual impairments (including blindness), serious emotional disturbance [...] orthopedic impairments, autism, traumatic brain injury, other health impairments, or specific learning disabilities" (Section 602, 3A, i).

Some students might require physical accommodations, which have nothing to do with their intelligence level, while others might require extra aid in certain subject areas, and others simply need help adapting to the school structure and the social atmosphere. The students in the latter group are usually the ones suffering from Asperger Syndrome. Asperger's gives a different definition to the term "special needs." These students need structure. They may need special accommodations within the classroom, such as a self-calming area, and most importantly, they need to learn how to adapt to different social environments (Farrell, 2004). The classroom can be overwhelming for these individuals; therefore, these students need counselors who are readily available along with school personnel who can aid with their social skills (Izzo, 2011). Clearly, schools are poorly informed of this disability. There are many interventions from which these students can benefit; however, schools fail to implement the proper interventions. Furthermore, due to the infamous label, some school districts are barring students from gifted programs (Grandin, 2005; Jurecic, 2007). . But many individuals with Asperger's are in fact gifted; they do, however, struggle with presenting themselves with poise and equanimity, causing society to perceive them as eccentrics (Farrell, 2004; Leech, 2004; Cowen, 2009).

\section{Mental Retardation and the DSM}

In 1952, the American Psychiatric Association compiled a list of possible mental illnesses known as the Diagnostic Statistical Manual for Mental Disorders (DSM). This manual served as a reference point for diagnosing individuals. The term "mental disorder" or "mental deficiency" was first documented 
in this manual. In the original DSM, "mental deficiency" described chronic brain disorders. In order to diagnose a brain disorder, the DSM measured one's degree of intelligence with an "Intelligence Quotient" (IQ) score. Mental deficiency was categorized into three groups: mild, moderate, and severe. The following table illustrates the assumed parallel between IQ scores and mental deficiency:

Table 1: Parallel between IQ scores and Mental Deficiency

\begin{tabular}{|l|l|}
\hline Classification & IQ Score \\
\hline Mild & $70-80$ \\
\hline Moderate & $50-70$ \\
\hline Severe & Below 50 \\
\hline
\end{tabular}

These abysmal IQ scores are usually associated with severe mental disorders, which do not allow the individual to function independently; such disorders are schizophrenia or Down syndrome. Clearly, the original DSM only labels the extreme cases as mental disorders. But who has the power to determine the criteria for this diagnosis? The American Psychiatric Association (APA) decides who is sane and who is not, and they persuade the public to accept their claims as being objective (Caplan, 1995). The eminent philosopher Michel Foucault (1975) supports this notion as he argues that mental professionals create the discourse on mental disorders, and they define the roles of madness and normalcy, deficiency and intelligence.

The APA created the DSM for universal use in the field of psychology to give mental therapists general criteria for all mental diagnoses. Yet, the DSM is more about politics than science. Presidential proclamations, committee decisions, and votes by APA members decide what counts as a psychiatric disorder, and what the symptoms should be (Breggin, 1994). The inclusion and exclusion of disorders is based on majority vote rather than indisputable empirical data, which deviates from biological or clinical reality (Zur \& Nordmarken, 2010; Breggin, 1994; Genova, 2003). The final published document is merely "the result of intensive campaigning, lengthy negotiating, infighting, and power plays" (Armstrong, 1993).

Since the original DSM had a limited number of diagnoses, mental therapists were in states of perplexity when attempting to diagnose patients. To rectify this problem, the DSM was forced to revise in 1968. Although the revision was necessary, the psychiatric world also used the DSM to serve as lucrative arrangement. In fact, the most recent DSM revision (DSM-IVTR) made over a million dollars in revenue for the APA (Caplan, 1995). Insurance companies require a DSM diagnosis to reimburse the patients and to compensate mental health professionals (Caplan, 1995; Spiegel 2005). In addition, DSM labels are utilized by court systems to determine insanity or incompetency; by schools to determine special educational needs or accommodations; by hospitals to determine treatments; and by government or social service agencies to determine custody of offspring (Caplan, 1995; Spiegel 2005). The DSM serves as method for social control, and while controlling individuals, the DSM manages to hoard money (Zur \& Nordmarken, 2010).

In the DSM-II, "mental deficiency" is recorded as "mental retardation." This new version of the DSM expanded to include borderline mental retardation and profound mental retardation. In addition, drastic changes were made to the IQ scores that qualified one as being "mentally retarded." The following table displays the new criteria:

Table 2: Changes made to the IQ Scores

\begin{tabular}{|l|l|}
\hline Classification & IQ Score \\
\hline Borderline & $68-85$ \\
\hline Mild & $52-67$ \\
\hline $\begin{array}{l}\text { Moderate } \\
\text { Severe }\end{array}$ & $36-51$ \\
\hline Profound & $20-25$ \\
\hline
\end{tabular}

One can see that there is a thirty-point difference between the DSM-I and DSM-II diagnosis for the strongest level of mental deficiency. But what do IQ tests prove? Can an IQ test accurately predict one's future success? Many researchers contend that IQ scores are erroneous; they do not accurately measure one's intelligence. Researchers such as Howard Gardner strongly assert that there is not one single way to measure intelligence, thus criticizing the concept of the ubiquitous standardized test. In his article, "IQ since 'The Bell Curve," Christopher F. Chabris presents myriad views on intelligence by psychometricians. Chabris (1998) explains that practitioners of pscyhometrics believe that although individuals have a wide range of intellectual abilities, there is a relationship among the variations, which attribute to a common factorgeneral intelligence. In addition, these practitioners believe that measurement is an indispensable operation, for "without a way to measure something it cannot be studied scientifically" (Chabris, 1998).

On the opposing side of this IQ test controversy, Howard Garner (1983) contends that general intelligence does not exist. Different parts of the brain are responsible for different abilities, and therefore, individuals have different types of intelligences, which cannot be determined by a universal test. In fact, in his book, Frames of Mind, Gardner (1993) castigates psychometrics while presenting the opposing side in the standardized test debate:

In the heyday of the psychometric and behaviorist eras, it was generally believed that intelligence was a single entity that was inherited; and that human beings — initially being a blank slate — could be trained to learn anything, provided that it was presented in an appropriate way. Nowadays an increasing number of researchers believe precisely the opposite; that there exists a multitude of intelligences, quite independent of each other; that each intelligence has its own strengths and constraints; that the mind is far from 
unencumbered at birth; and that it is unexpectedly difficult to teach things that go against early 'naïve' theories or that challenge the natural lines of force within an intelligence and its matching domains.

Table 3: Domains and IQ Scores

\begin{tabular}{|l|l|}
\hline Classification & IQ Score \\
\hline Borderline & $71-84$ \\
\hline Mild "educable" & $50-70$ \\
\hline $\begin{array}{l}\text { Moderate "trainable" } \\
\text { Severe }\end{array}$ & $35-49$ \\
\hline Profound & $20-34$ \\
\hline
\end{tabular}

With this new research, Gardner proposes the Theory of Multiple Intelligences. He has recently finalized his list to include nine intelligences: linguistic, logical-mathematical, spatial, musical, bodily kinesthetic, interpersonal, intrapersonal, naturalist, and existential. This finalized list stems from evidence surveyed from a wide range of the sciences, including biological, cultural, and psychological sciences (Chabris, 1998). Naturally, psychometricians ask how it is feasible to measure these various abilities, and Gardner simply replies, "“we don't measure them" (as cited in Chabris, 1998).

In a commentary on Chabris' article, Gardner criticizes the concept of the standard paper-and-pencil tests. He argues that due to the traditional setting in which the test are taken, these tests do not accurately measure intelligence. The tests are usually administered in classrooms or laboratories, they are timed, and they only consist of linguistic, logical, and sometimes spatial material (Chabris, 1998). This setting often leads to the pedagogy of teaching to the test; students are trained in this setting, and they are taught how to choose the proper answer on these tests - they are being taught how to take a test. Gardner challenges the practice of standardized tests by suggesting performance or authentic assessments. To accurately assay the multiple intelligences, these tests must be direct and naturaldeviating from paper-and-pencil. In addition, the tests must survey the intelligences in detail. We cannot rely on a one-time test to determine one's intelligence level. The multiple intelligences have many facets, and consequently, we cannot be satisfied with the first result from the test; there must be detailed analyses (Chabris, 1998).

Despite the IQ test controversy, the DSM continued to expand in 1980 and again in 1987. This third version of the DSM and the DSM-III-Revised included learning disabilities, such as Autism and Attention Deficit Disorder. According to the DSM-III, mental retardation is defined as "significantly subaverage general intellectual functioning resulting in, or associated with, deficits or impairments in adaptive behavior with onset before the age of 18" (3rd ed.; DSM-III; American Psychiatric Association, 1980).For the first time, the American
Psychiatric Association began to realize that diagnosing an individual solely on IQ scores is inaccurate. As a result, this new DSM diagnoses mental retardation by comparing IQ score with adaptive behavior. Although there are minute differences between the IQ scores used in the DSM-II and the IQ scores listed in the DSM-III, noting the changes is important.

Diagnosing a person as being mentally deficient based on IQ score is absurd. The false link between madness and knowledge demotes the "insane" or "mentally deficient" individuals to children: "'a new system of education must be applied, a new direction given to their ideas; they must first be subjugated, then encouraged, then applied to work, and this work made agreeable by attractive means"” (Foucault, 1988). Foucault (1975) censures the concept of knowledge and its relevance to the standard examination, arguing that the test is an inappropriate method for differentiating and judging individuals. The examination is a powerful tool acting upon the individual; it makes the individual docile, and demotes him to a position in which he can be measured, judged, described, and compared with others (Foucault, 1975). Perhaps Foucault's most explicit denunciation of the exam occurs in the following lines, as he explains how the exam has operated:

The examination opened up two correlative possibilities: firstly, the constitution of the individual as a describable, analyzable object, not in order to reduce him to 'specific' features, as did the naturalists in relation to living beings, but in order to maintain him in his individual features, in his particular evolution, in his own aptitudes or abilities, under the gaze of a permanent corpus of knowledge; and secondly, the constitution of a comparative system that made possible the measurement of overall phenomena, the description of groups, the characterization of collective facts, the calculation of the gaps between individuals, their distribution in a given 'population.' (Foucault, 1975)

This exam serves as a method for classifying individuals; people are categorized, and based on their test results, they are normalized, trained, chastened, excluded, etc. Thus, the individual is relegated to an object; one that can be descried by mental professionals who determine what knowledge is, and what is normal or acceptable behavior. Foucault also questions this idea of knowledge, and the group of superior individuals who decide what is correct. Once again, everything is political; a group of people (in this case the APA) congregates to decide what constitutes knowledge, and to consider ways in which they can use the power of knowledge as a method for control over their docile creatures.

Yet politics override the ideas and arguments of the philosophers, and the DSM continues to expand in order to thoroughly classify submissive individuals. In the fourth and latest edition of the DSM (the DSM-V will be published in May 2013), more learning disorders were added, including all of the Autism Spectrum Disorders, such as Asperger Syndrome. This version of the DSM continues to pair IQ scores with different levels of mental retardation with slight changes to the IQ scores from the DSM-III. 
But individuals with Asperger's cannot be diagnosed with this chart. They do not have low IQ scores; in fact, their IQ scores are usually above average. They do, however, lack receptive language, which affects their social skills. This information suggests that mental health professional cannot

Table 4: IQ Scores from DSM-III

\begin{tabular}{|l|l|}
\hline Classification & IQ Score \\
\hline Mild "educable" & $50-55$ to 70 \\
\hline Moderate "trainable" & $35-40$ to $50-55$ \\
\hline Severe & $20-25$ to $35-40$ \\
\hline Profound & Below 20 or 25 \\
\hline
\end{tabular}

always rely on the DSM. The DSM presents psychology as being in between the subjective and the objective. One psychologist may interpret a person's symptoms differently than another psychologist. Contrary to numerous blood tests or scanning devices which would render the same results for the same person, different psychologists might have different diagnoses for the same individual (Zur \& Nordmarken, 2010). Psychologists also fail to fathom that some psychological problems can arise from external forces rather than internal ones; not everything stems from a mental disorder. Therefore, the DSM influences mental health professionals in focusing solely on individuals' psyches, and using this as the determining factor in an individual's troubles (Caplan, 1995).

\section{Public Attitudes Toward Mental Disorders}

The stigma of the mentally ill did not begin with the DSM. In fact, during colonial times, individuals with mental illnesses were called "lunatics" (Satcher, 1999). The term "lunatic" was derived from the Latin word, "lunaticus"; the root, "luna," meaning moon. As clinicians began to relate madness to the phases of the moon, the word "lunatic" became associated with the mentally ill. A lunatic was one who experienced periodic insanity dependent on the changes of the moon. This definition stems from the symptoms of cyclical disorders, such as Bipolar Disorder or Cyclothymia, as the diagnosed individuals experience sudden changes in mood or behavior (Oxford English Dictionary, 2010). Furthermore, in the mid-1700s, the Pennsylvania Hospital in Philadelphia ostracized its mentally ill patients by placing them in the basement, while Virginia was the first state to establish an insane asylum to separate the mentally ill from the psychologically stable or 'normal' patients (Satcher, 1999). By ostracizing the mentally ill, the asylums gave the impression to the public that mental patients are pernicious to society.

During the classical age, madness was figured differently. Rather than perceiving the mentally ill as a danger to society, people perceived them as being idle and inefficient (Foucault, 1988). Since the mentally handicapped were unable to contribute to society through the use of labor, the government condemned them. Even in Nazi Germany, this figuration of madness existed. In fact, Germany euthanized the "mentally defective" because they were incapable of labor and were useless to society (Amen, 2002).

As the years progressed, the figuration of madness changed. Prior to the nineteenth century madness was figured as a spectacle - a source of entertainment for the 'normal' onlookers. The mentally ill were given the name "monster"; "the Latin word monstra, 'monster,' [...] means 'sign' and forms the root of our word demonstrate, meaning 'to show"' (Thomson, 1997). These "monsters" were placed in freak shows, allowing madness to become "a public scandal for the general delight" (Foucault, 1988). Clearly, the mentally deficient were not viewed as human beings; they were reduced to objects intended for display.

Nationally representative surveys conducted during the 1950 s display the public's negative view toward the mentally ill. The surveys found that only extreme forms of behavior were considered by the public to be the result of mental illnesses (Star, 1952, 1955). The surveys also suggested the social stigma attached to the mentally ill; the public feared "unpredictable and violent behavior" (Satcher, 1999) from the diagnosed individuals. Consequently, prior to the 1970s, several states had laws that explicitly prohibited children with mental disabilities from attending public schools (National Council on Disability, 2000).

According to the sixteenth surgeon general of the United States David Satcher (1999), the stigma given to the mentally ill individual leads to an onerous lifestyle. This individual is plagued with stereotypes while experiencing discrimination, ostracism, distrust, fear, discomfiture, ignominy, and/or anger; in severe cases, the individual suffers from physical and emotional abuse (Minow, 1987). Furthermore, Satcher (1999) contends that the notorious label causes 'normal' individuals to "avoid living, socializing or working with, renting to, or employing people with mental disorders." Clearly, the original defintion of the term "mental disorder" has led to negative views and actions toward those with the label. Due to the DSM's original diagnosis of a mentally deficient patient, the term "special needs" persists with a negative connotation in today's society regardless of the individual's condition.

\section{Special Needs and The Warnock Report}

The term "special needs" was first documented in 1978 in the Human Fertilisation Embryology Authority's (HFEA) publication of The Warnock Report. British philosopher Mary Warnock is known for her studies of morality, education, the mind, and existentialism. She is a prominent figure in Great Britain, and she is well known for her interest in the education of handicapped children. Consequently, she chaired a national committee of inquiry in Great Britain, which published the significant Warnock Report.

In chapter six of this report, Warnock gives a descriptive overview of special educational needs. She defines special educational need as the following:

A concept which $[\ldots]$ is serviceable in conveying the idea of a spread of children's needs, in contrast with the traditional system of discrete categories of disability. [...] individual needs are extremely variable in their intensity and composition. A particular disability varies widely in its severity from child to child and is often complicated by interaction with other handicapping conditions. (HFEA, 1978)

Contrary to the DSM, Warnock argues that children requiring special education have unique needs. She understands that students' disabilities range in severity, and therefore, they each require different interventions.

Warnock continues to explain the concept of special education by breaking it down into three categories. These 
categories do not limit a child to only one form of special educational need; the child will often qualify for more than one category. The categories are as follows:

(i) the need for the provision of special means of access to the curriculum, including specialist teaching techniques

(ii) the need for the provision of a special or modified curriculum

(iii) the need for particular attention to the social structure and emotional climate in which education takes place

Through these categories, Warnock focuses on the different aspects of educational need. She acknowledges that a special needs student must be taught differently, and she contends that instructors must alter their teaching methods to aid in the student's learning process. In addition, the curriculum must be adjusted to fit the student's needs, and the overall classroom environment should be evaluated in order to ensure that the learner is in a comfortable place that will not cause anxiety or disrupt the learning process.

\section{Asperger Syndrome and "the Geek Syndrome"}

For years psychologists have been researching the ubiquitous cognitive disability known as Asperger Syndrome. At first, people were poorly informed of this condition, but as the number of diagnoses burgeoned, the research expanded. In 1980, the DSM finally included Autism Spectrum Disorders, but due to the DSM's past descriptions of mental retardation, people viewed individuals with Asperger Syndrome negatively. Children with Asperger Syndrome fall under the Autism Spectrum, which places them into the mental retardation category, but in actuality these individuals might not have cognitive impairments. Before the DSM included Asperger's, people with this syndrome were labeled as "intellectually gifted" (Leech, 2003). As the disorder becomes more common and people are more cognizant, society begins to accept it. In fact, psychologist at the University of California, San Francisco, Bryna Siegel, believes that "it is now more socially acceptable to say a child is autistic, rather than mentally retarded" (cited in Abraham, 2002).

Individuals with Asperger Syndrome usually have average or in most cases above average IQ scores, their only problems are their social and communicative impairments (Leech, 2003). Since they lack receptive language, they usually have awkward gestures or remarks. Despite their social ineptitude, these individuals display their incredible knowledge in fields such as engineering or mathematics (Abraham, 2002; Cowen, 2009; Leech, 2003) Due to their academic success, Asperger Syndrome is now alluded to as "the Geek Syndrome" (Silberman, 2001; Abraham, 2002) or "the little-professor syndrome" (Farrell, 2004).

Individuals with Asperger's can be extremely tech savvy (Abraham, 2002; Leech, 2003). The Asperger traits allow them to have superior technical abilities such as complex analytical skills, and this causes many of these individuals to gravitate toward the computer programming industry (BBC, 2002). Computer science is a suitable career for an individual with Asperger's; "being able to systemise, that is, analyse the variables in a system and derive the underlying rules that govern that system, is known to be strong in Asperger's Syndrome" (Leech, 2003). Furthermore, computer programming requires minimal social interaction - another reason as to why it is an ideal job for a socially inept individual.

Autism researcher at the University of Cambridge, Simon Baron-Cohen (1999), has discovered several strengths in individual with Asperger's, arguing that Asperger's can be an advantage. His research concludes that individuals with Asperger Syndrome usually have superior pitch perception, excellent visual acuity, and strong memorization. They are also meticulous and easily notice details in patterns, they are rarely fooled by optical illusions, they solve puzzles at a fast rate, and they can perform difficult calculations in their heads (Cowen, 2009). In addition, Tyler Cowen (2009) discovered that "onethird of all autistics may have exceptional skills or savantlike abilities." These superior skills and abilities are part of the reason as to why individuals with Asperger's have become "the geek."

\section{What the Schools are Doing vs. What they should be Doing}

While there have been many interventions, the question remains: what are the schools doing, or rather what should they be doing? In his 2009 speech to the Joint Session of Congress, President Barack Obama said, "it will be the goal of this administration to ensure that every child has access to a complete and competitive education - from the day they are born to the day they begin their career." But has this goal been reached? At times, children with Asperger's do not always receive the proper educational interventions; therefore, schools need to do more for these students to ensure that they will prosper in the career world.

Public school districts have implemented Individualized Education Plans (IEP) for their special needs students. In section 614(d) of the 2004 Individuals with Disabilities Education Act (IDEA), IEP is defined as "a written statement for each child with a disability that is developed, reviewed, and revised." An IEP is required for all special needs students, and the IEP team must consist of the student, the parents, counselors, and teachers. The IEP meets throughout the school year to discuss the student's performance, his/her goals, and the transitional services that are readily available, such as occupational therapists or rehabilitation counselors (Izzo, 2011). The IEP team is also responsible in planning community experiences for the student, which will aid in achieving the student's goals and will prepare him/her for future employment (Izzo, 2011). Although the IEP aids the students throughout grade school, it is not doing enough to ensure that the student will be capable of functioning independently and succeeding in the workforce.

In one case, a school prevented an extremely intelligent student's future success by barring him from the "gifted program" due to his special needs label (Grandin, 2005; Jurecic, 2007). Although he was labeled as autistic, he would have been more appropriately diagnosed as Asperger's, but his autistic label prevented him from entering the program. As an individual who suffers from Asperger Syndrome, Dr. Temple Grandin (2005), asserts, "educators need to become aware that intellectually satisfying work makes life meaningful" for students with Asperger's; therefore, schools should not deny these students the right to challenge themselves intellectually, rather they should foster it.

With this information in mind, several researchers have suggested numerous effective interventions. As previously stated, many individuals with Asperger's are tech savvy; thus, Grandin (2005) suggests that these students should be taught 
using technology. In fact, section 611, C, iv of the 2004 IDEA, states that funds should be used "to improve the use of technology in the classroom by students with disabilities to enhance learning." While the chances of an Asperger's individual succeeding in the field of computer science is very high, implementing technology as an alternate teaching method can be beneficial to the student's overall learning process. For instance, assistant professor of political science at California State University Chico, Mallory Angeli (2009) believes that students with disabilities should have access to alternate forms of classroom material, including electronic text files. She supports this belief with University of California Berkeley's successful Assistive and Technology Teaching and Learning Center, which educates cognitively impaired students with the use of technology in order to help them achieve their educational goals. The use of technology alleviates some of the students' struggles by presenting the instructional material in familiar formats, and by using software systems that they can easily navigate (Angeli, 2009). In addition, students suffering from Asperger's usually prefer to communicate via writing, rather than through rapid conversations. Writing gives them more time to think and process their thoughts, and it does not give them social anxiety. Therefore, technology is a useful tool for communication, as the learners can use Internet forums, chat rooms, listservs, or blogs as an intellectual learning environment (Jurecic, 2007).

One of the main struggles for individuals with Asperger's is learning how to socialize. These individuals are socially inept, and they have difficulty interpreting other's emotions or body language. Therefore, Dr. Fred R. Volkmar, professor of child psychiatry, pediatrics, and psychology, and the director of the Yale University Child Study Center, suggests that schools should provide services to Asperger's students that focus on interpersonal skills (Farrell, 2004). Due to this new research, postsecondary education schools have implemented programs and have made accommodations for students with Asperger's, focusing mainly on social skills. In fact, "some colleges offer lessons in etiquette and social norms for Asperger's students" (Farrell, 2004). For example, Pittsburgh has implemented a program entitled Achieving in Higher Education with Autism and Developmental Disabilities to work with the students in local colleges on interpersonal skills and classroom behavior. The program founder and director, Carolyn Komich Hare, regularly checks in with the Asperger's students throughout the day to schedule their study time, help them with social situations, advise them on appropriate classroom behavior such as knowing when and how to ask questions, and she offers everyday social advice such as interacting with peers or asking a classmate out on a date (Farrell, 2004).

This program has proven to be successful, and many hope that the grade schools will begin to emulate this model for their special needs students. The program is based on the unique needs of individuals with Asperger Syndrome, and schools should implement similar programs, especially since IDEA (2004) states that educational services should be "designed to meet [special needs students'] unique needs and prepare them for further education, employment, and independent living" (Section 614, D, 1A). Since individuals with Asperger's are socially impaired, schools need to teach them how to interact well with others in order to prepare them for the career world, and to fulfill the IDEA requirement of meeting the unique needs of the individuals with disabilities.
By understanding how the mind works, Dr. James Gamble (2010), assistant professor of education at Ramapo College of New Jersey, former New Jersey School Superintendent, and author of several books and publications relating to brain based learning, suggests several effective classroom interventions. He first suggests that teachers provide as much structure as possible since students with Asperger's need some form of environmental structure to overcome their anxiety in a classroom setting. Gamble also suggests that teachers implement a self-calming area to which the student can escape if feeling overwhelmed. Teachers must be vigilant about the student's level of anxiety, and should attempt to eliminate it through structure, organization, and sensory motor areas. Instructors should also utilize visual prompts and give concrete examples. In addition, alternate modes of communication (e.g. communication via technology) should be available to the student. Consistent feedback is also effective in improving the student's learning and performance level, as individuals with Asperger's need guidance and direction. Instructors must also maintain communication between the home and the school (this can also be done through the IEP team), and most importantly, instructors must be patient and extend response time. Individuals with Asperger's need more time to process information and to prepare a response; therefore, teachers should not rush a response from the individual, as it will not be a fully developed thought (J. Gamble, lecture, November 17, 2010).

As Dr. Gamble suggests, Asperger students need structure. Tyler Cowen (2009) affirms this notion as he proves that the American University environment is quintessential for an individual with Asperger Syndrome, as the university allows for structure. In college, students have the freedom to choose the times of their classes and their work hours. They can also plan their study hours, and they have the ability to focus on projects and other course material for long periods of time, and they usually adhere to the same agenda each week. This is ideal for an individual suffering from Asperger Syndrome. These individuals prefer structured environments, and they need flexibility in choosing their hours of study and work. In addition, these individuals like to devote much of their time to one project, and having long breaks in their schedules allows them to do this. Perhaps if grade schools mirrored this structure, the Asperger students would perform better, and the number of special needs students achieving higher education would increase.

\section{Conclusion}

The American school district is not doing enough for students with special needs. Special education has become an abstract concept, but schools must attend to the students' unique needs in order to ensure future success. When dealing with individuals suffering from Asperger Syndrome, schools should implement programs that teach interpersonal skills to prepare them for the career world. Even basic social skills, such as interacting with classmates would be beneficial for these individuals. They need to learn how to communicate with their peers in order to prosper in the "real" world. Furthermore, Grandin (2005) believes that instructors should council their special needs students on entering fields that are suitable for them, such as computer programming, which requires the skills that many Asperger individuals tend to master. 
Teachers should also alter their pedagogy; one-to-one instruction can be effective for students with disabilities (Jurecic, 2007). Even changing the physical atmosphere can be effective. Sometimes the classroom setting is overwhelming and can evoke anxiety from an Asperger individual. By creating structure and designating a place for sensory motor breaks, the individuals with Asperger's will feel more relaxed. In addition to creating structure, the school personnel should council these individuals on planning their own structure in order to prevent feelings of anxiety. For instance, counselors can meet regularly with the individual to schedule study breaks throughout the day. Asperger students prefer stability; thus, by planning regular study breaks, and by adhering to the same schedule each day, the individual will have a greater chance of educational success.

Most importantly, schools need to know that not every intervention works for all special needs students. In fact, In Mary Warnock's Report, she argues the following in regards to intervention:

The range of provision needs to be extensive and flexible, to match as nearly as possible the extremely varied and changing needs of individual children. It should embrace different forms of provision in ordinary schools, as well as separate provision in special schools and other institutions. (HFEA, 1978)

Each student has unique needs; therefore, the school or the IEP team needs to discuss the options and test several different interventions to decide which ones work best, and from which ones the student can most benefit. The goal is to have these students with disabilities be capable of functioning independently after grade school, and the school system should prepare them for postsecondary education or for employment. If these special needs students do not receive the proper interventions, they will be deprived of future success.

\section{References}

Abraham, C. (2002). Is there a "geek" syndrome? The Globe and Mail. Retrieved from http://www.theglobeandmail.com/

Address to joint session of congress, Tuesday, February $24^{\text {th }}$, 2009. Washington DC: The While House. Retrieved from http://www.whitehouse.gov/the-press-office/remarkspresident-barack-obama-address-joint-session-congress

American Psychiatric Association (1952). Diagnostic and statistical manual of mental disorders. Washington, DC.

American Psychiatric Association (1968). Diagnostic and statistical manual of mental disorders-II. Washington, DC.

American Psychiatric Association. (1980). Diagnostic and statistical manual of mental disorders-III. Washington, DC.

American Psychiatric Association. (1987). Diagnostic and statistical manual of mental disorders-III-R. Washington, DC.

American Psychiatric Association (1994). Diagnostic and statistical manual of mental disorders-IV. Washington, DC.

American Psychiatric Association. (2000). Diagnostic and statistical manual of mental disorders-IV-TR. Washington, DC.

Angeli, M. (2009). Access and equality for all students: Meeting the needs of students with disabilities. CPEC. Retrieved from http://www.cpec.ca.gov/
Armstrong, L. (1993). And they call it help: The psychiatric policing of america's children. New York, NY: Basic Books.

Autism link to "geek genes." (2002). BBC News. Retrieved from http://news.bbc.co.uk/2/hi/health/2192611.stm

Baron-Cohen, S., Wheelwright, S., Stone, V., Rutherford, M. (1999). A mathematician, a physicist and a computer scientist with asperger syndrome: Performance on folk physics tests. Oxford University Press, 5. 475-83.

Breggin, P.R. (1994). Toxic psychiatry: Why therapy, empathy, and love must replace the drugs, electroshock, and biochemical theories of the new psychiatry. New York, NY: St Martins Press.

Caplan, P. J. (1995). They say you're crazy: How the world's most powerful psychiatrists decide who's normal. Reading, MA: Addison Wesley.

Chabris, C.F. (1998). IQ since "the bell curve." Commentary, 106 (2), 33-40. Retrieved from http://www.commentarymagazine.com/

Costa-Gavras. (Director). (2002) Amen [DVD]. France: Kino Video.

Cowen, T. (2009). Autism as academic paradigm. The Chronicle of Higher Education, 55. Retrieved from http://chronicle.com/section/Home/5

Farrell, E. F. (2004). Asperger's confounds colleges. The Chronicle of Higher Education. Retrieved from http://chronicle.com/section/Home/5

Foucault, M. (1975). Discipline and punish: The birth of the prison. New York, NY: Vintage Books.

Foucault, M. (1988). Madness and civilization: A history of insanity in the age of Reason. New York, NY: Vintage Books.

Gardner, Howard. (1983, 1993). Frames of Mind: The theory of multiple intelligences. New York: Basic Books.

Genova, P. (2003, April). Dump the DSM! Psychiatric Times, 20 (4). Retrieved from http://www.psychiatrictimes.com/p030472.html.

Grandin, T. (2005). Genius may be an abnormality: Educating students with asperger's syndrome, or high functioning autism. Autism Today. Retrieved from http://www.autismtoday.com/

Human Fertilisation Embryology Authority. (1978). The Warnock Report. London.

Izzo, M. (2011). Key roles in planning the transition to college and careers. Impact, 23 (2). Retrived from http://ici.umn.edu/products/impact/193/default.html

Jurecic, A. (2007). Neurodiversity. College English, 69 (5), 421. Retrieved from http://www.ncte.org/journals/ce

Leech, J. (2003). Brains, geeks, computers, and HCT. MSc Human Communication and Computing. Retrieved from http://www.cs.bath.ac.uk/hcc/

Minow, M. L. (1987). Interpreting rights: An essay for robert cover. 96 Yale Law Journal.

National Council on Disability. (2010). Back to school on civil rights. Retrieved from http://www.ncd.gov/publications/2000/Jan252000

Oxford English Dictionary ( ${ }^{\text {rd }}$ ed). (2010). New York, NY: Oxford University Press.

Satcher, D. (1999). Mental health: A report of the surgeon general. US Surgeon General Website. 
Silberman, S. The geek syndrome. Wired Magazine, 9 (11). Retrieved from http://www.wired.com/wired/archive/9.12/aspergers_pr.ht $\mathrm{ml}$

Spiegel, A. (2005, January). The dictionary of disorder: How one man redefined psychiatric care. The New Yorker, 5663.

Star, S.A. (1952). What the public thinks about mental health and mental illness. Paper presented at the annual meeting of the National Association for Mental Health.
Star, S.A. (1955). The public's ideas about mental illness. Paper presented at the annual meeting of the National Association for Mental Health.

Thomson, R. G. (1996) Extraordinary bodies: Figuring physical disability in american culture and literature. New York, NY: Columbia University Press.

United States Department of Education (2004). Individuals with disabilities improvement act. Washington, DC.

Zur, O. and Nordmarken, N. (2010). DSM: Diagnosing for money and power: Summary of the critique of the DSM. Retrieved from

http://www.zurinstitute.com/dsmcritique.html. 